\section{How to improve firm performance through employee diversity and organisational culture}

\author{
Rafael Triguero-Sánchez ${ }^{1}$ \\ Jesús Peña-Vinces ${ }^{1}$ \\ ${ }^{1}$ Universidad de Sevilla, Department of Business Management and Marketing, \\ Seville, Spain \\ Jorge Guillen ${ }^{2}$ \\ 2ESAN Graduate School of Business, Lima, Peru
}

\begin{abstract}
Purpose - Our study examines the influence that employee diversity has on human resource management (HRM) practices and organisational performance, considering the moderating role of organisational culture, in particular, cultural dimensions such as individualism-collectivism and hierarchical distance.
\end{abstract}

Design/methodology/approach - Through an empirical investigation of 102 Spanish firms using partial least squares-structural equation modelling (PLS-SEM), we evaluated our hypotheses.

Findings - Our results show a positive correlation between employee diversity and HRM practices where such practices encourage employee commitment rather than control. Thus, we identified a non-linear relationship between HRM practices and organisational performance.

Originality/value - The study considers the role played by environmental and contextual factors, such as organisational culture. The configuring of HR practices may help to reduce the possible costs derived from a diverse staff and improve their skills in favour of better organisational performance.

Keywords - Employee diversity, HRM practices, individualismcollectivism, hierarchical distance, organisational performance
Received on

03/06/2017

Approved on

$02 / 02 / 2018$

Responsible editor:

Prof. Dr. Joao Maurício

Boaventura

Evaluation process:

Double Blind Review

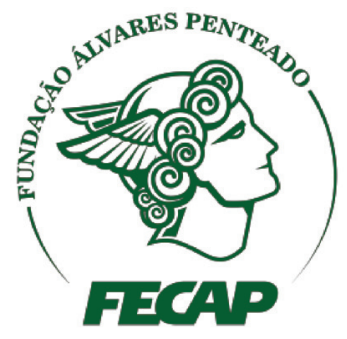

Review of Business

Management
DOI: $10.7819 /$ rbgn.v20i3.3303 


\section{Introduction}

Researchers have devoted much effort in recent years to studying the relationship between human resource management (HRM) and organisational performance, and a particular case of this relationship, which is the focus of this study, is when a firm's human resources (HR) are characterised by diversity in terms of demographic characteristics (gender, age, race or nationality) (Knippenberg \& Schippers, 2007) and/or human capital (education, functional speciality, length of service in the organisation or in the position) (Triguero-Sánchez, Peña-Vinces, Gonzalez-Rendon \& Sánchez-Apellániz, 2012).

Though the literature shows that human resource diversity can have positive effects on the success of organisations (i.e. Chatman $\&$ Flynn, 2001; Chattopadhyay \& George, 2001), there is no consensus regarding the effects of this heterogeneity and even the very concept of diversity is not exempt from discussion. Some studies (i.e. Knippenberg \& Schippers, 2007) have shown that the types of diversity - functional and demographic - do not by themselves explain their effects on the performance of work groups or of the organisation (Triguero-sánchez, PeñaVinces \& Sánchez-Apellániz, 2011). Moreover, the idea that there is a straightforward and direct relationship between diversity and performance has been questioned. More attention to the intermediate variables in this relationship, such as human resource practices and other contextual variables, has been demanded (i.e. Malik, Waheed \& Malik, 2010; Richard, Murthi \& Ismail, 2007). Diversity models must, therefore, include environmental variables/factors that can explain the process (Martin-Alcázar, Romero \& Sánchez-Gardey, 2011; Shore \& Coyle-Shapiro, 2003). It has also been stated that dimensions of organisational culture (Hofstede, 1980, 1994) and/or organisational climate (Bowen \& Ostroff, 2004) provide a solid base for these kinds of studies.

Therefore, our research has a double aim. On one hand, it shows how diversity among employees and conditions of the HR system influence organisational performance, taking contextual variables into account. On the other hand, as a second aim, with the same importance as the first, we assess the moderating effect of the cultural dimensions of individualism-collectivism (IC) and hierarchical distance (HD). This moderating impact may affect the relationship between HRM practices and performance. We must consider that the relevance of these dimensions is derived from studying organisational culture (Hofstede, 2001) and, especially, studies that aim at fostering employee commitment and organisational performance relationships. These relationships are evaluated from a perspective linked to social exchange theory (SET) (Bordia, Restubog, Bordia \& Tang, 2017; Cropanzano \& Mitchell, 2005; Martin-Alcázar et al., 2011; Shore \& Coyle-Shapiro, 2003). Lastly, this work also contributes to the measurement of organisational performance from a non-financial perspective. In other words, we assess organisational performance in terms of employees' and managers' perceptions of their organisations' achievements.

Our research is structured as follows. First, the fundamental concepts are addressed, considering the relationship between HR diversity and organisational performance. The possible moderating effects of IC and HD cultural dimensions are studied through the mediation of HRM. The key findings are provided after an analysis of the results, addressing the limitations of this paper, followed by the new research lines that emerge and the implications for management.

\section{Theoretical Framework and Hypotheses}

Studies that focus on employee diversity have mainly centred on differences in gender, age, race, the nationality of origin, educational level, functional background and length of service (Milliken \& Martins, 1996; Sujin, 2005). Whatever diversity variable is analysed, the intention is to explain how the differences between the members of a work team affect its performance 
(Knippenberg \& Schippers, 2007). Studies on this matter from the fields of social psychology and management deal with the impact of diversity on business success (Prieto, Phipps \& Osiri, 2009). The similarity-attraction paradigm, along with the social categorisation perspective (Tziner, 1985), show that homogeneous groups or teams are probably more productive than heterogeneous ones due to the mutual attraction between members with similar characteristics (Wiersema \& Bantel, 1992). Cognitive diversity theory (Cox $\&$ Blake, 1991) and the information/decisionmaking perspective, however, emphasise the benefits of diverse work groups and, in particular, the breadth of opinions and outlooks that they generate (Knippenberg \& Schippers, 2007), as well as their actions and results (Hambrick \& Mason, 1984). The way employees interpret and use information is influenced by their cognitive diversity (Dahlin, Weingart \& Hinds, 2005) and has been related to a broader vision of the organisation and greater response capacity, as well as fostering debate and participation (Pitcher $\&$ Smith, 2001).

In the management field, the benefits of diversity include greater creativity, innovation and problem-solving capacity (Cox \& Blake, 1991; Hambrick, Cho \& Chen, 1996). From the resource-based view, this has been regarded as a source of competitive advantage (i.e. Barney \& Wright, 1998). Thus, an organisation's growth and its success are limited/propelled by the deployment of its resources to achieve new and innovative forms of advantage over the competition (Paauwe, 2004). In this vein, Richard et al. (2007) show that a diverse workforce in organisations indirectly influences performance, generally showing its effects through HR practices (Triguero-Sánchez et al., 2011).

For many of those who study HRM, diversity among employees is an essential element since it affects the level of knowledge, adeptness and skills they contribute to their organisations. At the same time, HRM systems can positively influence employee attitudes and behaviour by improving the work atmosphere (Richard \& Johnson, 2001), thereby enhancing performance (Bowen \& Ostroff, 2004). HRM practices affect organisational performance through their effect on employee development and behaviours. These practices determine the type of employees who are selected, the skills and motivation of the employees, and the opportunities and incentives they have to design new and better ways of doing their jobs (Moideenkutty, Al-Lamki \& Rama Murthy, 2011). The common theme in the literature that relates human resource management with business results places emphasis on the use of systems that can achieve a possible source of competitive advantage. In this sense, HRM practices could be a good system by which to provide a competitive advantage for a firm (Triguero-Sánchez et al., 2011, 2012). Therefore, these aspects must be considered when designing and implementing an HRM system (Richard \& Johnson, 2001). Among the approaches concerning the configuration of HR policies and practices, for our study we have preferred a social exchange perspective (Cropanzano \& Mitchell, 2005) that underlines reciprocal interdependence in which 'one party's actions are contingent on the other's behaviour' (Blau, 1964; Bowen \& Ostroff, 2004; Cropanzano \& Mitchell, 2005). This approach indicates that different components must be appropriately aligned with each other to achieve the performance that organisations wish for (Hartman \& Moers, 1999), and its effectiveness depends significantly on contextual and environmental characteristics (Bowen \& Ostroff, 2004).

Furthermore, the literature suggests that the composition of work groups must ensure suitable skills as well as creating mechanisms to stimulate and motivate the workers. This work system would allow employees to contribute, through their individual and collective efforts, to securing the organisation's results (TrigueroSánchez et al., 2011). Arguments founded on the ability-motivation-opportunity theoretical approach (Boxal \& Purcell, 2003) enable the set 
of HR practices to be defined and structured. According to Coyle-Shapiro, Morrow and Kessler (2006), SET provides a sufficient basis for understanding the relationship between employees' work and their commitment, from various points of view. According to Golparvar and Javadian (2012), the individual-organisational perceptions of justice or injustice that predict individual behaviour are derived from this. That is, the exchange relationships are likely derived from the belief of the employee, in which unfair rules will lower the level of commitment to the organisation (Bordia et al., 2017). These arguments are also supported by the contingency approach to HRM, as it focuses more on commitment than on mere compliance (Alcázar, Fernández \& Gardey, 2005). Our study is also based on social exchange theory inasmuch as it focuses on employee commitment (Cropanzano \& Mitchell, 2005). Despite the difference in this theory (i.e. Coyle-Shapiro \& Conway, 2004), there is broad agreement that interactions between group members inevitably force them to relate to each other (Coyle-Shapiro \& Conway, 2004). This approach implies that the exchange of tangible and intangible resources is ruled by norms of reciprocity (Gouldner, 1960 ) and the underlying assumptions (Hatch \& Cunliffe, 2006) that guide behaviour in such a way that one person feels obliged to return favours received from another person. In the long term, this becomes a mechanism of reinforcement between them. This theory has had a special influence on 'individual-organisation' relations in that it supports HRM, which seeks commitment from employees by favouring their integration in the firm and the achievement of aims (Guest, Michie \& Conway, 2003; Kirkman \& Shapiro, 2001). From this perspective, HR practices can be classified by their orientation, either seeking to control employees or their commitment to the organisation (Richard \& Johnson, 2001). This argument is strengthened by Bowen and Ostroff (2004). They indicated that HRM systems must integrate their content (practices and policies) with their processes (e.g. through commitment) to be efficient. Furthermore, the participation of workers in their group's decisions, the search for agreement between them and the avoidance of interpersonal conflicts require management systems that allow open discussions of their points of view, especially if they differ (Bowen \& Ostroff, 2004). The management of diverse employees will be more efficient in promoting their commitment to the company, while these employees will feel more integrated and highly regarded by the organisation (Triguero-Sánchez et al., 2012). This way, cohesion and communication between employees and their working groups are strengthened, which should improve the quality of their decision-making processes and, consequently, lead to improvements in production processes (McMillan-Capehart, 2005). Improvements that tend to remain over time (Muchiri \& Ayuko, 2013) may be moderated by contextual and cultural elements (Richard et al., 2007). To sum up, there is a broad consensus on the benefits that are generated by enhancing the commitment of employees to their work teams and their organisations. From this perspective, our model seeks to explore HR policies that mediate in the 'diversity-performance' causality chain through HRM practices geared towards employee commitment (see Figure1).

Considering the above, we set forth the following hypotheses:

Hypothesis 1A (+): Greater diversity among the employees of an organisation will positively influence HRM practices that boost employee commitment.

Hypothesis 1B (+): HRM practices that foster employee commitment will positively influence the performance of an organisation.

The moderating variables can be situated in the HRM practices-performance relationship from a superior order perspective (Ferris, Arthur, Berkson, Kaplan, Harrell-Cook \& Frink, 1998) and refer to the role of the organisation's structure 
and culture. Their name is a reference to the social structures that cannot be reduced to a mere sum of the perceptions of those that make up the organisation (Bowen \& Ostroff, 2004). From this view, culture can function as a background to the HRM system and as a mediator of its link to the firm's performance (Denison, 1996).

Jaques (1951) defined firm culture as the usual and traditional way of thinking and doing things. A firm's culture is, to a greater or lesser degree, shared by all its members and has a high impact on HR policies and the HRM system as a whole, determining acceptance of the rules and forms of learning (Pheng \& Yuquan, 2002). Founders' and leaders' values will inspire the practices of their employees, moderating and/ or conditioning them. This is why culture is especially important for our model (Knippenberg \& Schippers, 2007; Martin-Alcázar et al., 2011; Shore \& Coyle-Shapiro, 2003), and in this vein, recent studies consider that the processes and factors that mediate between HRM practices and performance must be investigated. The cultural dimensions (Hofstede, 1980) researchers have paid most attention to are individualismcollectivism (IC), corresponding to the essential aspects of behaviour in the organisation, and hierarchical distance (HD), which expresses differences in status and power, due to their close relationship with decision-making and communication efficiency (Jackson, 2002; Lam, Chen \& Schaubroeck, 2002) and, consequently, their importance in the HRM system. Along the same lines, Fischer and Mansell (2009) argued in favour of the existence of a relationship between employee commitment and IC and HD dimensions. Therefore, IC and HD are the two moderating variables in this study.

\section{I Individualism-collectivism in the organisation}

IC, considered as opposite poles of the same culture dimension, are defined as the individualism that belongs to societies in which the link between people is slight, and the collectivism, as an opposite reality, that characterises societies in which people are integrated from their birth in strong and united groups which will continue to protect each other in exchange for unquestionable loyalty (Hofstede, 1994).

Therefore, the degree of IC prevailing in an organisation's culture will affect the relationship between individuals and the organisation they work for (Triguero-Sánchez et al., 2011), employees' attitudes and their behavioural intentions through their perception of the level of fairness (Ramamoorthy \& Flood, 2002) and the team's loyalty and its pro-social behaviour (Ramamoorthy \& Flood, 2004). If a high degree of collectivism characterises an organisation, the employees will seek to maintain harmonious relationships in the group even though they do so at the expense of sacrificing the completion of tasks. They will prefer cooperative approaches such as negotiation, mediation and consensus in resolving conflicts (Triandis, Bontempo, Villareal, Asai \& Lucca, 1988). Along these lines, Kirkman and Shapiro (2001) detected a positive relationship between the prevalence of cultures with high collectivism and their members' level of satisfaction, as well as greater commitment to their organisations. This affects the social atmosphere and, therefore, results (Pan, French, Goldschmidt \& Song, 2006). Jackson (2002) also found a positive relationship between predominant collectivism in an organisational culture and practices geared towards seeking employee commitment. In our case, it is of interest to know if the HRM practices-performance relationship is moderated by the cultural dimension (IC).

Therefore:

Hypothesis 2A (+): Higher collectivism among the employees of an organisation will favour (positively moderate) the influence of HRM practices on organisational performance.

\subsection{Hierarchical distance in the organisation}

Hierarchical distance (HD), also known as power distance, refers to the degree to which 
people expect the differences in status between subordinates and superiors to be emphasised. In organisations marked by a high HD, distinct differences will be expected that represent the existing inequality (Hofstede, 1980). Therefore, those in which power is distributed unequally tend to be accepted. HD is determined by the organisational structure, the participation of people in decision-making, the characteristics of the communication processes and the particularities of the firm's employees. These establish the guidelines for the relationships and conflicts that emerge in the heart of the company. Jiing-Li, Niara and Jian (2007) showed that a lower HD between the members of work groups helps to improve their performance and that of the organisation. When a high HD prevails, the manager fulfils the role of an autocratic boss who strongly relies on set rules (Bu, Craig \& Peng, 2001) and the subordinate expects to be told what to do (Pheng \& Yuquan, 2002). Relationships between superiors and subordinates are highly formal, resulting in strictly differentiated roles which are likely to generate paternalistic attitudes and polarised (very positive or very negative) feelings. In brief, as with IC, HD must be considered in the design of the practices, as they can influence the HR practices-performance relationship (Triguero-Sánchez et al., 2011). Therefore:

Hypothesis 2B (-): A greater hierarchical distance between an organisation's employees will negatively moderate the impact of HRM practices on organisational performance.

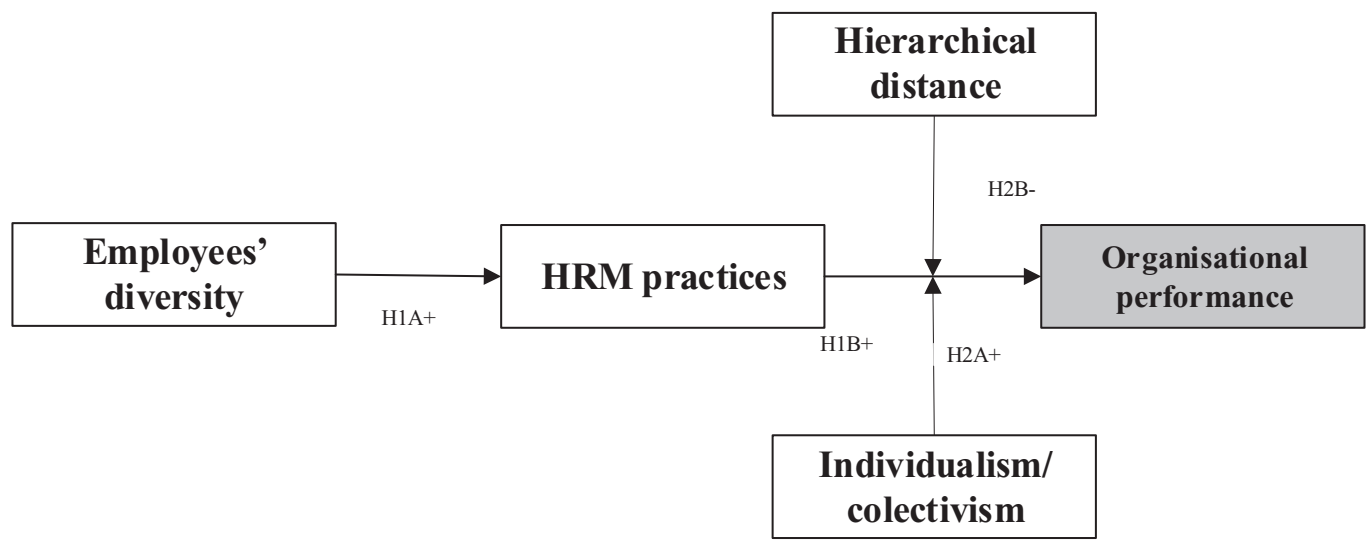

Figure 1. The proposed theoretical model.

\section{Method}

\section{I Sample and data collection}

The process followed to complete the questionnaires is supported by the HRM scientific literature (Guest et al., 2003). Regarding the unit sample, the questionnaires were answered by the managers of HR, chairs of HR and general directors.

The relevant people in each company were phoned, during which time they were assured of the relevance of taking part in the study and also of its usefulness. If so required, we committed to sending them the results of the research. They were also assured that the information would be dealt with confidentially, globally and anonymously. Finally, we highlighted the importance of the suggestions that the interviewees proposed to us and our gratitude for their participation. All these aspects were emphasised in the introductory letter which was later sent along with the questionnaire and a prepaid envelope for return upon completion.

The companies were selected from the IBAS (Iberian Balances Analysis System) (SABI 
2009 in Spanish) database. Among the registered companies, 1,300 had between 100 and 2,000 employees, according to the data registered in 2007, and 1,169 were founded before 2003 . The resulting population was 902 companies, which offered a well-balanced representation of all productive sectors. In addition to verifying the data collected from the IBAS database with each organisation, a total of 103 questionnaires were returned in different forms: via email, post, online survey (web survey) and personal interviews in organisations. This represents a reply rate of $11.42 \%$.

The low reply rate is because our research population was obtained exclusively from the IBAS database. For a firm to be part of the study it had to fulfil the following requirements: at least 30 employees; a minimum of seven years operating in the market; the geographical location had to be within the Andalucía region of Spain; and it had to have an HR manager. Thus, once the selection criteria were applied, the sample size was reduced.
Our sample is representative of the population of study (IBAS database), which makes it adequate and appropriate to examine the moderating effect of HD on the HRM practices-OP relationship.

Concerning the nature of the companies, 93\% belonged to the private sector and the remainder to the public sector - in other words, they belonged to the Spanish government.

The information at this stage of the investigation was examined using the partial least squares-structural equation modelling (PLSSEM) methodology (Chin, 2003) and SPSS v. 20 (IBM Corp. 2013). This consists of evaluating a model in two stages (measurement model and structural model). The PLS-SEM procedure has gained interest and has been applied by researchers in recent years (Chin, 1998; Real, Leal \& Roldán, 2006).

The following tables (Tables 1 and 2) summarise the descriptive statistics of the unit of analysis.

Table 1

\section{The survey's technical data}

\begin{tabular}{ll}
\hline Population size & 902 Firms \\
Universe & HR directors and CEOs \\
Place of study & Andalucía (Spain) \\
Sampling method de la information & Survey: via email, postal survey and personal interviews \\
Sample size & 102 surveys (discounting those that were ineligible and/or incomplete) \\
Time period & June 2009 to October 2009 \\
\hline
\end{tabular}

Table 2

The sample's statistical characteristics

\begin{tabular}{lccccc}
\hline Characteristics & N & Minimum & Maximum & Mean & SD \\
\hline Years of operations & 97 & 7 & 86 & 20.90 & 12.28 \\
Number of employees & 102 & 30 & 1,720 & 218.03 & 265.59 \\
Total assets (last three years) in euros & 102 & 327,393 & $416,598,667$ & $37,051,984$ & $65,657,472$ \\
\hline
\end{tabular}

Note. SD: standard deviation, $N$ : this refers to the number of firms 


\subsection{Measures}

The literature was consulted to obtain a reliable measurement, using tools broadly validated and verified in previous investigations.

\subsection{Measures of HRM practices and measures of cultural dimensions}

The variables used to measure HR practices are supported in the existing literature using Guest et al.'s (2003) measuring items, with a seven-point Likert-type scale ( $1=$ low commitment and higher control, 7 = high commitment and low control). Aspects such as personnel recruitment, training, evaluation, job flexibility, job design, level of communication, job stability, equal opportunities and HRM quality were measured. These aspects provide information on the orientation of the HR strategies in the companies studied, following Guest et al. (2003), which satisfies some of the Meyer and Allen's (1997) recommendations.

\subsection{I.I Cultural dimensions variables}

Measures of individualism-collectivism and hierarchical distance were derived from Baker, Carson and Carson's (2009) adaptation of the scale proposed by Dorfman and Howell (1988) using a seven-point Likert-scale, where 1 = fully disagree and 7 = fully agree. We assume that if there is a high level of collectivism in the company, there is little or no individualism. Six items were used for each of the dimensions analysed, and the statements were of the kind: 'Group success is more import than individual success'.

\subsubsection{Measure of employee diversity}

Although the previously analysed literature shows there is an extensive range of measures to evaluate demographic and human capital diversity, this research measured aspects related to age, gender, race and nationality. In the human capital factors, aspects connected to the level of education, the level of specialisation, seniority in the organisation and seniority in the workplace were measured. Levie's (2006) tests were used to validate demographic factors. The measurement scale developed by Boone, Olffen, Witteloostuijn and Brabander (2004) and confirmed by Cannella, Park and Lee (2008) was used to evaluate human capital factors. We asked for the approximate percentage in each category. For instance, in the case of age, we asked for an approximate proportion of employees under 36 years old.

These measures have been incorporated into the diversity construct by Blau's index of heterogeneity - broadly accepted in social and behavioural sciences (Gibson, Waller, Carpenter \& Conte, 2007; Richard, Barnett, Dwyver \& Chadwick, 2004). The following expression represents Blau's index (1977):

$$
I=1-\sum P_{i}^{2}
$$

where $\mathrm{P}$ is the proportion of people in each category studied and ' $\mathrm{i}$ ' is the number of categories observed (Gibson et al., 2007; Richard et al., 2004), while each factor of diversity is an item of the diversity construct. In short, this construct was measured using six items, from age to employee length of service (see full items in the appendix).

\subsubsection{Measure of organisational performance}

The relationship between HRM and organisational performance (OP) is based on two key arguments. The first considers this as a source of competitive advantage (Barney, 1991); the second that its efficiency depends on the application of HR practice management systems. Bontis, Hulland and Crossan's (2002) measurement scale was used to measure OP. Therefore, following Nonaka's (1994) theoretical proposal, OP was measured at the individual level, group level and at the level of the whole organisation. This measurement scale, introduced by Bontis (1999) and continued by Bontis et al. (2002), has become very popular among academics (Triguero-Sánchez et al., 2011). We emphasise this in the use of a seven-point Likert-scale, in which 1 $=$ fully disagree and 7 = fully agree . 


\subsubsection{Measures of control variable}

According to the literature on performance measurement, almost all studies that assess OP regarding some aspect of organisations always use control variables, and this has two critical foundations. Firstly, the objective is to obtain a 'parsimonious model', and secondly, OP depends on multiple factors or areas of the company. Therefore, the following measurement items were used: 1) Firm size was measured by the number of employees working in the company; 2) Industrial sector and categorization from the National Institute of Statistics in Spain, which classifies economic sectors into agriculture, industry and construction, trade and restoration, transportation and communications, services to firms and other services. Following Gooderham, Parry and Ringdal's (2008) recommendations, the economic sector to which a firm belongs was categorised based on its contribution to Spanish GDP. Using a seven-point Likert scale ( 1 = least important, 7 = most important); 3) Firm age - following previous research (Peña-Vinces \& Urbano, 2014), the number of years operating in the market was used. Additionally, the mean of the last three years of the firm's total assets was used as a control variable.

Table 3

\section{Results of the measurement model}

\begin{tabular}{|c|c|c|c|}
\hline Constructs/dimension/indicator & Loading & CR & $\mathrm{AVE}$ \\
\hline Individualism-Collectivism (IC) & & .948 & .751 \\
\hline \multicolumn{4}{|l|}{ (common latent construct) } \\
\hline Wellness of the groups versus individual rewards & .880 & & \\
\hline Success of group & .881 & & \\
\hline Acceptance within the working groups & .884 & & \\
\hline Pursuit of collective goals & .884 & & \\
\hline Loyalty of management to the working groups & .889 & & \\
\hline Organisational rather than individual goals & .756 & & \\
\hline Hierarchical distance (HD) & & .924 & .670 \\
\hline \multicolumn{4}{|l|}{ (common latent construct) } \\
\hline Abuse of authority and power & .864 & & \\
\hline Participation of subordinates in business decisions & .827 & & \\
\hline
\end{tabular}

\section{$3 \cdot 3$ Results}

Our research model is made up of six constructs, two of which are second order (HRM practices and OP). After transforming secondorder constructs into first-order constructs for inclusion in the research model, reflective and formative constructs must be differentiated as they require different statistical treatments (Chin, 2003). The data in our study (Table 3 ) on the formative constructs have no multicollinearity problems as their values are well below the limit of 3.30 established by Roberts and Thatcher (2009) [variance inflation factor (VIF), VIF $\leq 3.30$ ].

As can be seen from Table 3, the analyses of the reliability of the items in the case of the reflective constructs show values higher than 0.70. According to Nunnally (1978), the next step in evaluating the measurement model (first step) is the analysis of convergent validity, obtained through the average variance extracted (AVE) (Barclay, Higgins \& Thompson, 1995). Fornell and Larcker (1981) recommend that the AVE be greater than 0.50. As Table 3 shows, the model records fair values, and these are never below $67 \%$. As an additional evaluation, the discriminant validity of the construct was analysed. As Table 4 shows, the correlations between constructs are lower than the square root of the AVE. 


\begin{tabular}{|c|c|c|c|}
\hline Constructs/dimension/indicator & Loading & CR & AVE \\
\hline Consideration of the views of employees & .887 & & \\
\hline Social relations between managers and employees & .719 & & \\
\hline Acceptance of authority by employees & .829 & & \\
\hline Empowerment & .781 & & \\
\hline HRM practices & & .951 & .685 \\
\hline \multicolumn{4}{|l|}{ (Second-order common latent construct) } \\
\hline Evaluation & .760 & & \\
\hline Bidirectional communication & .787 & & \\
\hline Job design & .897 & & \\
\hline Equality & .902 & & \\
\hline Flexible remuneration & .735 & & \\
\hline Training & .846 & & \\
\hline Job quality & .944 & & \\
\hline Selection & .716 & & \\
\hline Job stability & .827 & & \\
\hline Organisational Performance (OP) & & .882 & .715 \\
\hline \multicolumn{4}{|l|}{ (Second-order common latent construct) } \\
\hline Individual performance & 909 & & \\
\hline Group performance & .818 & & \\
\hline Organisational performance & .806 & & \\
\hline $\begin{array}{l}\text { Employee diversity (ED) } \\
\text { (Formative construct) }\end{array}$ & Weight & Tolerance & VIF \\
\hline Age & .408 & .863 & 1.159 \\
\hline Gender & -.233 & .684 & 1.462 \\
\hline Race & -.138 & .362 & 2.762 \\
\hline Nationality & .009 & .308 & 3.248 \\
\hline Education & -.022 & .882 & 1.133 \\
\hline Function & .573 & .718 & 1.393 \\
\hline Length of service & -.344 & .436 & 2.293 \\
\hline Seniority & -.081 & .442 & 2.262 \\
\hline \multicolumn{4}{|l|}{ Control variable (CV) } \\
\hline Industrial sectors & .481 & .727 & 1.376 \\
\hline Firm size & -.191 & .721 & 1.386 \\
\hline Firm assets & .797 & .990 & 1.010 \\
\hline Firm age & -.548 & .954 & 1.048 \\
\hline
\end{tabular}

Note. VIF: Variance inflation factor; CR: Composed reliability; AVE: Average variance extracted 
Table 4

\section{Discriminant validity coefficients}

\begin{tabular}{|c|c|c|c|c|c|c|c|c|}
\hline & Mean & SD & (1) & (2) & (3) & (4) & (5) & (6) \\
\hline (1) Employee diversity & 0.340 & 0.094 & N.A & & & & & \\
\hline (2) Individualism-Collectivism & 4.531 & 1.566 & -0.398 & 0.867 & & & & \\
\hline (3) Hierarchical distance & 3.543 & 1.591 & 0.317 & 0.000 & 0.819 & & & \\
\hline (4) HRM practices & 4.052 & 1.249 & $0.364^{*}$ & $0.698^{*}$ & $-0.267^{*}$ & 0.827 & & \\
\hline (5) Organisational performance & 5.437 & 0.861 & 0.004 & 0.148 & 0.204 & $.708^{*}$ & 0.845 & \\
\hline (6) Control variable & 7.619 & 3.486 & N.A. & N.A. & N.A. & N.A. & -0.141 & N.A. \\
\hline
\end{tabular}

Note. Mean is the average score for all items in this measure. SD: standard deviation. The italic numbers of the diagonal are the square root of AVE, and off-diagonal elements are correlations between constructs.

Significant $={ }^{*} p<.05 ; \mathrm{NA}=$ not applicable

After confirming the measurement model validity and reliability, it was necessary to assess whether the structural model (SM) supports the proposed model (second step); that is to say, the existing relationships between the latent variables according to the theory that is used as a basis for constructing this model (Chin, 2003). The SM was tested considering the intensity of the path coefficients or the weight of the standardised regression and the variance explained $\left(R^{2}\right)$ of the endogenous or dependent variables. The non-parametric bootstrapping technique was applied to evaluate the precision and stability of the estimates obtained. This provides the meaning of the structural roads and, along with this, whether the proposed hypothesis is supported by the standard error and the Student $T$ values of the parameters of this model (Chin, 2003).

Additionally, predictive relevance was evaluated through $Q^{2}$, and the requirement for $Q^{2}$ to be greater than zero $\left(Q^{2}>0.00\right)$ was met. Finally, the results confirm that the structural model has predictive quality, obtaining a Goodness-of-Fit (GOF) far from zero and close to one (Tenenhaus, 2008) (see Figure 2).

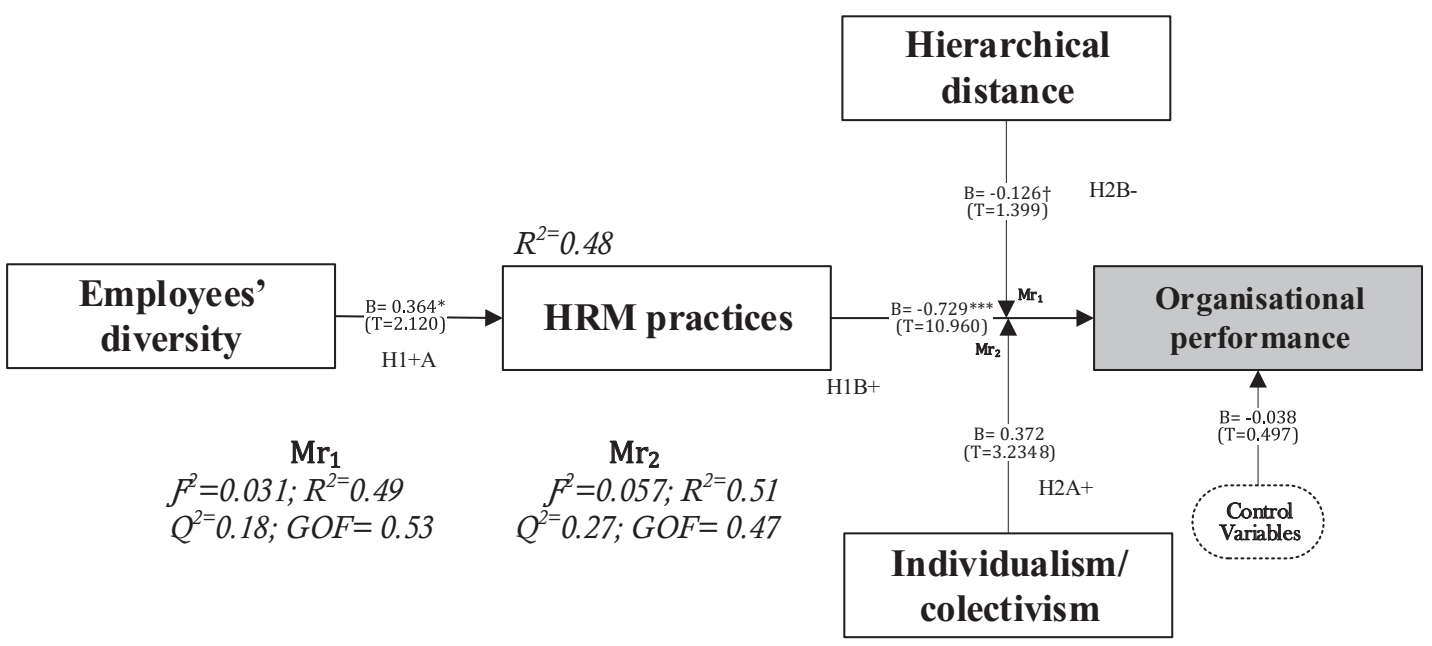

Figure 2. Results of research model 
Note.

$\rightarrow$ hypothesised sample;

$B=$ Path coefficients;

$\mathrm{T}=T$-values/bootstrap;

$f^{2}=$ Effect size

$Q^{2}=$ Predictive relevance;

GOF $=$ Goodness-of-fit index

$\mathrm{Mr}_{(\mathbf{1}, 2)}=$ Moderator relationships

$\dagger p<0.1 ;^{*} p<0.05 ;{ }^{* *} p<0.01 ;{ }^{* * *} p<0.001$

\section{Discussion of the Results}

In coherence with previous studies (Chatman \& Flynn, 2001; Chattopadhyay \& George, 2001; Moideenkutty, Al-Lamki \& Rama Murthy, 2011; Richard \& Johnson, 2001; Triguero-Sánchez et al., 2011), hypothesis H1A $(B=0.364 ; p<.05)$ is confirmed, in that a higher level of diversity among the employees of an organisation positively influences HRM practices (see Figure 2).

Regarding hypothesis H1B $(\beta=0.729$; $p<.001)$, our results show that HRM practices favouring employee commitment benefits organizational performance. In fact, the correlation matrix corroborates this statement (non-significant correlation between OP and ED equal to 0.004; see Table 4). Thus, diversity is shown to be a determinant of the functioning of any HR practices. This finding matches most of the existent literature (Bamberger \& Meshoulam, 2000; Kirkman \& Shapiro, 2001; Martin-Alcázar et al., 2011). Therefore, we confirm hypothesis H1B.

Concerning H2B $(\beta=-0.126 ; p<.1)$ and H2A $(\beta=0.372 ; p<.001)$ and considering the moderating effects posed in the assumptions, it is evident that there is no direct linear relationship between employee diversity and organisational performance. Therefore, these two hypotheses have statistical support to confirm its role as a moderator. Thus, the cultural variables, hierarchical distance and individualism-collectivism influence the relationship between HRM practices and organisational performance. In this sense, the moderating effect of individualism-collectivism indicates that a higher level of collectivism favours company performance, given that HRM practices have a more considerable orientation towards commitment than control (according to Jackson, 2002; Triguero-Sánchez et al., 2011). Meanwhile, a lower hierarchical distance is associated with a more significant orientation towards commitment (or little control) (Bu et al., 2001; Kirkman \& Shapiro, 2001).

Regarding our control variables, they did not all show a positive effect on organisational performance $(\beta=0.038)$, which contradicts the values we expected. Since there is no empirical support to reject or support these variables, we justify their inclusion (Triguero-Sánchez et al., 2012) as they allow a greater control of the phenomenon studied. We would like to comment on the values for 'Industrial Sectors' and 'Firm Assets', which have been shown to be statistically significant with positive values (Weight $=.481$ and .797 , respectively), while 'Firm Size' has a negative weight (W = -191) and 'Firm Age' (W $=-548$ ) did not present an appropriate level of significance.

\section{Moderator relationship}

Once the linear model was analysed, the moderating effect of HD and IC on organisational performance was examined following the recommendations of Henseler, Fassott, Dijkstra and Wilson (2011). They propose a two-stage approach to estimate the effect of size $(f)$ in order to determine if the moderator variable fulfils its role in a non-linear relationship (see Henseler et al., 2011; Ng \& Feldman, 2010). Following the rule of thumb established by these authors, values of $0.02 / 0.15 / 0.35$ are regarded as weak/moderate/ high, respectively. In our case, for $\mathrm{HD}, f$ is 0.031 , and for IC, the value is 0.057 . Therefore, we can conclude that the moderating effects of HD and IC are slight (see the values for $\mathrm{Mr}_{1}$ and $\mathrm{Mr}_{2}$ in Figure 2).

Furthermore, concerning the analysis of possible changes in $\mathrm{R}^{2}$ between the model without a moderating effect and the model with 
a moderating effect ( $\mathrm{Ng} \&$ Feldman, 2010), our results show that when the moderator variables (HD and IC) are introduced, the explained variance of organisational performance increases slightly, going from $R^{2}=0.48$ to $R^{2}=0.49$, for the case of the HD variable, and from $R^{2}=0.48$ to $R^{2}=0.51$ for IC (see the values for $\mathrm{Mr}_{1}$ and $\mathrm{Mr}_{2}$ in Figure 2).

Moreover, the relationships between the moderator variables show statistical significance, although HD has a weak predictive value $(\beta=-0.126)$ and IC quite a good one $(\beta=0.372)$.

A first contribution can be deduced from the moderating character of the cultural dimensions analysed in the model, in that they successfully contribute to firm performance. This finding is consistent with the literature reviewed (i.e. Jiing-Lih et al., 2007). The results also show the benefits of diversity when HRM is oriented towards achieving the commitment of employees rather than towards controlling them (Kirkman \& Shapiro, 2001; Shahnawaz \& Juval, 2006), hence the importance of considering the determining factors of diversity when designing an HR practices system. On the contrary, it could be suggested that if an organisation has HRM practices oriented towards greater control, it would obtain better results if high HD and a greater individualism prevail.

A second contribution can be gained from the validity of the model, since it incorporates dimensions of organisational culture that help to explain the phenomenon, shedding some light on the understanding of the so-called Black Box (Lawrence, 1997, which connects diversity with firm performance). The data are ratified by the relevance and predictive quality of the research model (see values for $\mathrm{Mr}_{1}$ and $\mathrm{Mr}_{2}$ ).

\section{Conclusions}

It is clear that many studies have dealt with the effects on organisations of the driving factors of diversity as a condition of HRM practices (Triguero-Sánchez et al., 2011; Richard, 2000; Richard et al., 2004). Our study has shown that the seniority of employees in an organisation is essential, followed by their age and the country of origin as elements to be considered when configuring an HRM practices system.

The data show that organisations' HR policies and practices have positive effects on organisational performance when they strive to gain employee commitment; far from presenting a direct relationship between the level of diversity and an organisation's performance, this emerges as being measured by HRM practices (along the same lines: Richard, 2000; Richard et al., 2004).

Our results indicate that HR policies and practices oriented towards seeking employee commitment, and not control, are conditioned by diversity such that performance improves when firms have a diverse workforce in terms of age and functional speciality (Sujin, 2005).

Furthermore, all the studied aspects of HRM practices in our model showed positive effects on organisational performance. In particular, these include practices related to 'quality in the workplace' such as 'quality programmes' in management, employee participation in solving organisational problems, the establishment of 'quality circles', the existence of 'teamwork improvements' and, to a large extent, the achievement of 'employee commitment' through quality assurance in their jobs. At the same time, we detected that the activities carried out by organisations for all employees to benefit from 'equal opportunities' are a valuable indicator of HR practices. The design of work positions is another HR practice that allows the 'existence of multifunctional teams', where an adequate 'job design' or existence of 'suitably qualified employees' with regard to the attributed and/ or attributable competencies (flexibility) play an essential role in configuring competitive advantage; that is, they contribute to improving performance.

Employee training and stability also proved to be critical factors, especially in some key positions, where these aspects are considered crucial for the organisation's future and employees' 
career paths. Furthermore, along with job design, the selection process also plays an important role in organisations, especially regarding the commitment of future employees. Evaluation was also shown to be highly relevant in HRM. One example would be companies informing their employees about the economic and financial situation to achieve their involvement, commitment and cooperation towards the shared objectives. Therefore, communication is another prominent factor in achieving such results. Finally, the policy of offering incentives based on work performance (awards for productivity, group performance and share of the profits) also appears as an essential factor in HR practices.

Additionally, the results show the moderating effect of cultural dimensions on the HRM practices-OP relationship, although there is only a small moderating effect for IC and HD.

HD moderated the relationship, improving their positive effects when the levels to go down. That is to say, when HD was lower, the effects of the integrating policies were perceived as better by the employees and directors. Regarding the IC dimension, its moderating effects on the HRM practices-OP relationship was positive when the levels of collectivism improved.

Regarding the implications for management, our research model suggests that configuring HR practices may help to reduce the possible costs derived from a diverse staff and improve their skills in favour of better OP. What must be especially considered are how the workforce is made up and the orientation of the HR system, considering the role played by environmental and contextual factors, such as organisational culture. Our study invites HR experts to optimise the positive effects of diversity via strategies based on policies that favour the commitment of employees to their work groups and the firm.

Moreover, employees and managers perceive organisations with shorter power distances as being more efficient, and a shorter power distance also contributes to the application of HR policies, finally reflecting on OP. Hence, employees in organisations which seek their commitment benefit from organisational cultures in which 'horizontal structures' (e.g. < HD) are prevalent, and there is little vertical distance and/or hierarchy between employees. Therefore, when organisations design their HRM plans and strategies, they should pay close attention to their organisational culture.

Furthermore, if organisations wish to achieve higher commitment from their employees, the HR manager's decision-making should be based on query initiatives before they appeal to higher authorities. Actions such as delegating important tasks to employees enable participation in decisions on management issues or the development of social relationships outside the company. In general, these HR practices tend to strengthen the relationship between the different hierarchical levels of organisations. Therefore, the correct utilisation of HRM practices will contribute to better results.

This is the case of performance evaluation actions, having in place periodical bidirectional communication plans and personnel recruitment. In any case, these are all practices focusing on employee integration, and so, far from being designed and implemented apart from other personnel organisational actions, they must build up one single and coherent HR management system. This argument has been shown to be valid in collectivist environments provided that such management systems consider the commitment of employees to their work groups. This will result in better management of interpersonal conflicts, greater participation and a higher level of consensus in the pursuit of solutions and agreement among (Triguero-Sánchez et at., 2011) work group members.

This research model offers suggestions for new research lines, especially those that continue to look more deeply into the Black Box between diversity and its effects. Hence, we consider the following to be of interest for more thorough study: 1) Adding the social dynamics of work groups to the research model so that this aids in understanding of the effects on the different processes; 2) Looking more deeply into each of the decisive factors of diversity, differentiating 
the demographic aspects from those of human capital, since their repercussions on the efficiency of the work groups are supposed to be unequal; 3) Studying new moderating variables in the relationships between the variables studied, both of organisational culture and others that are contextual; and 4) Using other different cultural dimensions.

Another exciting research line within our model would be the inclusion of cultural variables such as support from senior management of diversity policies and a participatory culture among employees.

A limitation of the study derives from it being carried out in a specific region, with its own particular culture. Therefore, more studies in other geographical areas with different cultures are needed to generalise the results.

\section{References}

Alcázar, F. M., Fernández, P. M. R., \& Gardey, G. S. (2005). Researching on SHRM: An analysis of the debate over the role Played by Human Resources in Firm Success. Management Review, 116 (2), 213-241.

Baker, D., Carson, K., \& Carson, P. (2009). An individual-level examination of the impact of cultural value on organizational identification. Journal of Applied Management and Entrepreneurship, 14(2), 29-44.

Bamberger, P., \& Meshoulam, L. (2000). Human resource strategy: Formulation implementation and impact. Thousand Oaks: Sage Publishing.

Barclay, D., Higgins, C., \& Thompson, R. (1995). The partial least squares (PLS) approach to causal modelling: Personal computer adoption and use as an illustration. Technology Studies, 2(2), 285-309.

Barney, J. B. (1991). Firm resources and sustained competitive advantage. Journal of Management, 17(1) 99-120.

Barney, J. B., \& Wright, P. M. (1998). On becoming a strategic partner: The role of human resources in gaining competitive advantage. Human Resource Management, 37(1), 31-46.

Blau, P. M. (1964). Exchange and power in social life. New York: Wiley.

Blau, P. M. (1977). Inequality and Heterogeneity. New York: Free Press.

Bontis, N. (1999). Managing an organizational learning system by aligning stocks and flows of knowledge: An empirical examination of intellectual capital knowledge management and business performance (UMI Dissertations). University of Western Ontario.

Bontis, N., Hulland, J., \& Crossan, M. M. (2002). Managing an organizational learning system by aligning stocks and flows. Journal of Management Studies, 39(4), 437-469.

Boone, C.., Olffen, W. van, Witteloostuijn A. van, \& Brabander, B. de. (2004). The genesis of top management team diversity: Selective turnover among top management teams in Dutch newspaper publishing 1970-94. Academy of Management Journal, 47(5), 633-656.

Bordia, P, Restubog, S. L L., Bordia, S., \& Tang, R. L. (2017). Effects of resource availability on social exchange relationships: The case of employee psychological contract obligations. Journal of Management, 43(5), 1447-1471.

Bowen, D. E., \& Ostroff, C. (2004). Understanding HRM-firm performance linkages: The roles of the "strength" of the HRM System. Academy of Management Review, 29(2), 203-221.

Boxal, P., \& Purcell, J. (2003). Strategy and human resource management. Palgrave Macmillan: Basingstoke.

Bu, N., Craig, T. J., \& Peng, T. K. (2001). Acceptance of supervisory direction in typical workplace situations. International Journal of Cross-Cultural, 1(2), 131-152. 
Cannella, A., Park, J., \& Lee, H. (2008). Top management team functional background diversity and firm performance: Examining the roles of team member collocation and environmental uncertainty. Academy of Management Journal, 51(4), 768-784.

Chatman, J., \& Flynn, F. (2001). The influence of demographic composition on the emergence and consequences of cooperative norms in work groups. Academy of Management Journal, 44(5), 956-974.

Chattopadhyay, P., \& George, E. (2001). Examining the effects of work externalization through the lens of social identity theory. Journal of Applied Psychology, 86(4), 781-788.

Chin, W.W. (1998). Issues and opinion on structural equation modeling. MIS Quarterly, 22(1), 7-21.

Chin, W.W. (2003). PLS-Graph (Version 03.00 Build 1058) (computer software) University of Houston

Cox, T. H., \& Blake, S. (1991). Managing cultural diversity: implications for organizational competitiveness. Academy of Management Executive, 5(3), 45-56.

Coyle-Shapiro, J. A. M., \& Conway N. (2004). The employment relationship through the lens of social exchange. In J. A.. M. Coyle-Shapiro, L. J. Shore, M. S. Taylor, \& L. E. Tetricks (Eds.) The employment relationship: Examining psychological and contextual perspectives. (pp. 5-28). Oxford UK: Oxford University Press.

Coyle-Shapiro, J. A. M., Morrow, P. C., \& Kessler, I. (2006). Serving two organizations: exploring the employment relationship of contracted employees. Human Resource Management, 45(4), 561-583.

Cropanzano, R., \& Mitchell, M. S. (2005). Social exchange theory: An interdisciplinary review. Journal of Management, 31(6), 874-900.
Dahlin, K. B., Weingart, L. R., \& Hinds, P. J. (2005). Team diversity and information use. Academy of Management Journal, 48(6), 1107-1123.

Denison, D. R. (1996). What is the difference between culture and organizational climate? A native's point of view on a decade of paradigm wars. Academy of Management Review, 21(3), 619-654.

Dorfman, P.W., \& Howell, J. P. (1988). Dimensions of national culture and effective leadership patterns: Hofstede revisited. In R. N. Famer, Advances in International Comparative Management (Advances in International Management, Vol. 3, pp. 127-150). Bradford: Emerald Group Publishing.

Ferris, G. F., Arthur, M. M., Berkson, H. M., Kaplan, D. M, Harrell-Cook, G., \& Frink D. D. (1998). Toward a social context theory of the Human Resource Management-Organization effectiveness relationship. Human Resource Management Review, 8(3), 235-264.

Fischer, R., \& Mansell, A. (2009). Commitment across cultures. A meta-analytical approach. Journal of International Business, 4O(2), 13391358.

Fornell, C., \& Larcker, D. F. (1981). Evaluating structural equation models with unobservable variables and measurement error. Journal of Marketing Research, 18(1), 39-50.

Gibson, C. B., Waller, M. J., Carpenter M., \& Conte, J. M. (2007). Antecedents consequences and moderators of time perspective heterogeneity for knowledge management in MNO teams. Journal of Organizational Behavior, 28(8), 1005-1034.

Golparvar, M., \& Javadian, Z. (2012). The relationship between perceived organizational justice and $\mathrm{OCBs}$ with consider moderating role of equity sensitivity: Some cultural implications. International Journal of Psychological Studies, 4(2), 28-41. 
Gooderham, P., Parry, E., \& Ringdal, K. (2008). The impact of bundles of strategic human resource management practices on the performance of European firms. International Journal of Human Resource Management, 19(11), 2041-2056.

Gouldner, A.W. (1960). The norm of reciprocity: A preliminary tatement American Sociological Review, 25(2), 161-178.

Guest, D. E., Michie, J., \& Conway, M. (2003). Human resource management and corporate performance in the UK. British Journal of Industrial Relations, 41(2), 291-314.

Hambrick, D. C., Cho, T. S., \& Chen, M. J. (1996). The influence of TMT heterogeneity on firms' competitive moves. Administrative Science Quarterly, 41(4), 659-684.

Hambrick, D. C., \& Mason, P. A. (1984). Upper echelons: The organization as a reflection of its top managers. Academy of Management Review, 9(2), 193-206.

Hartman, F. G., \& Moers, F. (1999). Testing contingency hypotheses in budgetary research: An evaluation of the use of moderated regression analysis. Accounting Organizations and Society, 24(4), 291-315.

Hatch, M. J., \& Cunliffe, A. L. (2006). Organization theory. Oxford, UK: Oxford University Press.

Henseler, J., Fassott, G., Dijkstra, T. K., \& Wilson, B. (2011). Analyzing quadratic effects of formative constructs by means of variance-based structural equation modeling. European Journal of Information Systems, 21(1), 99-112.

Hofstede, G. (1980). Culture's Consequences: International Differences in Work-Related Values. Thousand Oaks: Sage Publications.

Hofstede, G. (1994). Culture and Organizations Intercultural Cooperation and its Importance for Survival. HarperCollins
Hofstede, G. (2001). Culture's consequences: Comparing values, behaviors, institutions, and organizations across nations (2nd ed.). Thousand Oaks, Sage Publications. CA. The USA.

IBM Corp. (2013). IBM SPSS Statistics for Windows, Version 22.0. Armonk, NY: IBM Corp Jackson, T. (2002). The management of people across cultures: Valuing people differently. Human Resource Management, 41(4), 455-475.

Jaques, E. (1951). The changing culture of a factory. Oxford England: Tavistock

Jiing-Lih, F., Niara, D. H., \& Jian, L. (2007). Individual level cultural values as moderators of perceived organizational support-employee outcome relationships in China: Comparing the effects of power distance and traditionality. Academy of Management Journal, 50(3), 715-729.

Kirkman, B. L. \& Shapiro, D. L. (2001). The impact of cultural values on job satisfaction and organizational commitment in self-managing work teams: The mediating role of employee resistance. Academy of Management Journal, 44(3), 557.

Knippenberg, D. van, \& Schippers, M. C. (2007). Work Group Diversity. Annual Review of Psychology, 58, 515-41.

Lam, S. K., Chen, X., \& Schaubroeck, J. (2002). Participative decision making and employee performance in different cultures: The moderating effects of allocentrism/idiocentrism and efficacy. Academy of Management Journal, 45(5), 905-914.

Lawrence, B. (1997). The black box of organization demography. Organization Science, 8(1), 1-22.

Levie, J. (2006). Inmigration in-migration ethnicity and entrepreneurship in the United Kingdom. Small Business Economics, 28, 143-169.

Malik, O.F., Waheed A. \& Malik, K. (2010). The mediating effects of job satisfaction on role stressors and affective commitment. International 
Journal of Business and Management, 5(11), 223237.

Martin-Alcazar, F. Romero, P., \& Sánchez-Gardey, G. S. (2011). Effects of diversity on group decision-making processes: The moderating role of human resource management. Group Decision and Negotiation, 21(5), 677-701.

McMillan-Capehart, A. (2005). A configurational framework for diversity: Socialization and culture. Personnel Review, 34(4), 488-503.

Meyer, J. P., \& Allen, N. (1997). Two (o more?) dimensions of organizational commitment: Reexamination of the affective and continuance commitment scales. Journal of Applied Psychology, 72(4), 638-642.

Milliken, F. J., \& Martins, L. .L. (1996). Searching for common threads: Understanding the multiple effects of diversity in organizational groups. Academy of Management Review, 21(2), 402-433.

Moideenkutty, U., Al-Lamki, A., \& Rama Murthy, Y. S. (2011). HRM practices and organizational performance in Oman. Personnel Review, 40(2), 239-251.

Muchiri, M. K. \& Ayoko, O. B. (2013). Linking demographic diversity to organizational outcomes. The moderating role of transformational leadership. Leadership \& Organization Development Journal, 34 (5), 384-406.

Ng, T. W., \& Feldman, D. C. (2010). Human capital and objective indicators of career success: The mediating effects of cognitive ability and conscientiousness. Journal of Occupational and Organizational Psychology, 83(1), 207-235.

Nonaka, I. (1994). A dynamic theory of organizational knowledge creation. Organization Science, 1(1), 14-37.

Nunnally, J. (1978). Psychometric theory. New York.: McGraw-Hill.
Paauwe, J. (2004). HRM and performance: Achieving long term viability. Oxford: Oxford University Press.

Pan, Y., French, W., Goldschmidt, A., \& Song, X. (2006). An exploration of work-related values among young executives in China and the United States. American Marketing Association Conference Proceedings 17, pp. 177-178.

Peña-Vinces, J. C., \& Urbano D. (2014). The Influence of domestic economic agents on the international competitiveness of Latin American firms: Evidence from Peruvian small and medium multinational enterprises. Emerging Markets Finance and Trade, 50(6), 43-63.

Pheng, L. S., \& Yuquan, S. (2002). An exploratory study of Hofstede's cross-cultural dimensions in construction projects. Management Decision, 4O(1), 7-16.

Pitcher, P., \& Smith, A. D. (2001). Top management team heterogeneity: Personality power and proxies. Organization Science, 12(1), $1-18$.

Prieto, L. C., Phipps, S. T. A., \& Osiri, J. K. (2009). Linking workplace diversity to organizational performance: A conceptual framework. Journal of Diversity Management, 4(4), 13-22.

Ramamoorthy, N., \& Flood, P. C. (2002). Employee attitudes and behavioral intentions: A test of the main and moderating effects of individualism-collectivism orientations. Human Relations, 55(9), 1071-1096.

Ramamoorthy, N., \& Flood, P. C. (2004). Individualism/collectivism perceived task interdependence and teamwork attitudes among Irish blue-collar employees: A test of the main and moderating effects. Human Relations, 57(3), 347-366.

Real, J. C., Leal, A., \& Roldán, J. L. (2006). Information technology as a determinant of organizational learning and technological 
distinctive competencies. Industrial Marketing Management, 35(4), 505-521.

Richard, O. C. (2000). Racial diversity business strategy and firm performance: A resource-based view. Academy of Management Journal, 43(2), 164-177.

Richard, O. C., Barnett, T., Dwyver, S. N., \& Chadwick, K. (2004). Cultural diversity in management, firm performance, and the moderating role of entrepreneurial orientation dimensions. Academy of Management Journal, 47(2), 255-266.

Richard, O. C., \& Johnson, N. B. (2001). Understanding the impact of human resource diversity practices on firm performance. Journal of Managerial, 13(2), 177-195.

Richard, O. C., Murthi, B. P., \& Ismail, K. (2007). The impact of racial diversity on intermediate and long-term performance: The moderating role of environmental context. Strategic Management Journal, 28, 1213-1233.

Roberts, N., \& Thatcher, J. (2009). Conceptualizing and testing formative constructs: Tutorial and annotated example. The Data Base for Advances in Information Systems, 40(3), 9-39.

SABI (2009). Iberian Annual Review System. http://sabi.bvdep.com (28 May, 2009)

Shahnawaz, M. G., \& Juyal, R. C. (2006). HRM practices and organizational commitment in different organizations. Journal of the Indian Academy of Applied Psychology, 32(3), 171-178.

Shore, L. M., \& Coyle-Shapiro, J. (2003). New developments in the employee-organization relationship. Journal of Organizational Behavior, 24(5), 443-450.
Sujin, L. (2005). Judgment of ingroups and outgroups in intra and intercultural negotiation: The role of interdependent self-construal in judgment timing. Group Decision and Negotation, 14(1), 43-62.

Tenenhaus, M. (2008). Component-based structural equation modelling. Total Quality Management and Business Excellence, 19(7), 871-886.

Triandis, H. C., Bontempo, R., Villareal, M. J., Asai, M., \& Lucca, N. (1988). Individualism and collectivism: Cross-cultural perspectives on selfingroup relationships. Journal of Personality and Social Psychology, 54(2), 323-338.

Triguero-Sánchez, R., Peña-Vinces, J. C., \& Sánchez-Apellániz, M. (2011). HRM in Spain its diversity and the role of organizational culture: an empirical study. European Journal of Social Sciences, 26(3), 389-407.

Triguero-Sánchez, R., Peña-Vinces, J. C., González-Rendon, M., \& Sánchez-Apellániz, M. (2012). Human resource management practices aimed at seeking the commitment of employees on financial and non-financial (subjective) performance in Spanish firms: An empirical contribution. Journal of Economics Finance and Administrative Science, 17(32), 17-30.

Tziner, A. (1985). How team composition affects task performance: Some theoretical insights. Psychological Reports, 57(3), 1111-1119.

Wiersema, M. F., \& Bantel, K. A. (1992). TMT demography and corporate strategic change. Academy of Management Journal, 35(1), 91-121. 


\section{Appendix}

This is a study concerning HRM diversity in Spain.

The survey is confidential, and we never reveal personal information.

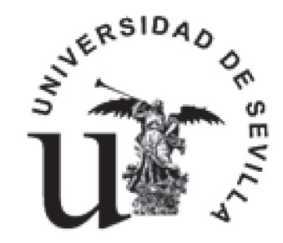

Company name

E-mail

Phone

Job position

For the next several questions, please choose a number from 1 to 7 next to each statement to indicate how much you agree or not.

\begin{tabular}{|c|c|c|c|c|c|c|c|c|}
\hline $1=$ fully disagree dagree & \multicolumn{8}{|c|}{7 = fully agree. } \\
\hline Hierarchical distance & & 1 & 2 & 3 & 4 & 5 & 6 & 7 \\
\hline \multicolumn{9}{|c|}{ Managers make the vast majority of decisions without consulting their subordinates } \\
\hline \multicolumn{9}{|c|}{ Managers often take advantage of their authority and power to deal with their subordinates } \\
\hline \multicolumn{9}{|l|}{ On rare occasions, managers ask the opinions of their subordinates } \\
\hline \multicolumn{9}{|c|}{ Directors avoid having social relationships with employees out of work } \\
\hline \multicolumn{9}{|l|}{ Employees will not discuss management decisions } \\
\hline \multicolumn{9}{|l|}{ Managers do not delegate the necessary tasks to subordinates } \\
\hline Individualism-Collectivism & & 1 & 2 & 3 & 4 & 5 & 6 & 7 \\
\hline \multicolumn{9}{|c|}{ In our organisation, group well-being is more important than individual rewards } \\
\hline \multicolumn{9}{|l|}{ The success of the team is more important than individual success } \\
\hline \multicolumn{9}{|l|}{ It is essential that the employees are accepted by the working groups } \\
\hline \multicolumn{9}{|c|}{$\begin{array}{l}\text { In our company, employees try to achieve their personal goals by taking into account what is best for the } \\
\text { group }\end{array}$} \\
\hline \multicolumn{9}{|c|}{ The directors tend to be loyal and support the team, even if individual goals are affected } \\
\hline \multicolumn{9}{|c|}{ In our company, people are expected to abondon their personal goals if asked to do so } \\
\hline HRM practices & & 1 & 2 & 3 & 4 & 5 & 6 & 7 \\
\hline \multicolumn{9}{|l|}{ Selection } \\
\hline \multicolumn{9}{|c|}{ Our company has recruitment and selection processes to fill all the available vacancies } \\
\hline \multicolumn{9}{|c|}{ As part of the selection process, applicants are informed about the negative aspects of the job } \\
\hline \multicolumn{9}{|c|}{$\begin{array}{l}\text { In our company, we have developed systems to select personnel (in addition to interviews and/or } \\
\text { curriculum analysis) }\end{array}$} \\
\hline \multicolumn{9}{|l|}{ Training } \\
\hline \multicolumn{9}{|c|}{ Our firm offers training for those positions considered to be 'key positions' } \\
\hline \multicolumn{9}{|c|}{ All employees receive training for their jobs (without any legal requirement) } \\
\hline When employees receive training, their performance improves & & & & & & & & \\
\hline
\end{tabular}


When employees receive training, it is often relevant to their future/career in the company (job promotions)

A performance appraisal generally measures non-management employees

Non-management employees receive part of their salary based on performance

Usually, non-management employees are informed of their performance through information provided by third parties (e.g. superiors, customers, suppliers

Flexible remuneration

Non-management employees are remunerated according to their performance

Non-management employees are remunerated according to their group performance

Non-management employees have the right to receive monetary incentives

Non-management employees have the right to receive other types of incentives, such as profit-sharing, bonuses, recognition

Job design

There is an active implementation of self-managed or self-directed teams

There is a robust implementation of multifunctional teams

There is a strong presence of 'project-based teams.'

There is a robust implementation of flexi-jobs (flexi-time, online work, video conferencing, measures to strike a balance between work and family life)

Most jobs have been designed for employees to optimise their skills and strengths

Most employees are well qualified or can develop new skills

Employees are given the opportunity to change jobs

Bidirectional communication

The firm provides its employees with regular information about business operations and business behaviour

Employees are consulted regarding their views and opinions

The firm provides employees with information about the business plan on a regular basis

The organisation has mechanisms to consult employees about plans and future projects of the firm

We consult employee representatives before setting the performance target (individual, group)

Job stability

Internal promotion fills vacancies that require experience

The organisation regularly allows internal promotion

The organisation is committed to securing job stability

Employees are often made redundant

Equality

The organisation carries out actions to ensure that all employees have equal opportunities

Job quality

The organisation gives employees the opportunity to engage in problem-solving situations

The organisation has a strong presence in quality circles

The organisation facilitates the involvement of its employees in improving teamwork

Employees feel committed when assured of the quality of their work

Organisational performance

필. Individuals are satisfied working here

莺

Individuals are satisfied with their performance

Our group makes a substantial contribution to the organisation

窎密 Our group performs well as a team

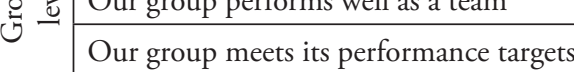




\begin{tabular}{|c|c|c|}
\hline \multirow{4}{*}{ 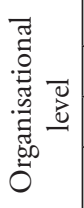 } & Our organisation is successful & \\
\hline & Our organisation meets its clients' needs & \\
\hline & Our organisation's future performance is secure & \\
\hline & Our organisation is well-respected within the industry & \\
\hline \multicolumn{3}{|c|}{ Employees' diversity } \\
\hline \multirow{2}{*}{$\stackrel{0}{\&}$} & Approximate $\%$ of employees in your organisation's workforce less than 36 years old & $\%$ \\
\hline & Approximate \% of employees in your organisation's workforce between 36 and 45 years old & $\%$ \\
\hline \multirow{2}{*}{$\begin{array}{l}\ddot{\Xi} \\
\vec{\Xi} \\
\tilde{v}\end{array}$} & Approximate $\%$ of women working in your company in relation to total & $\%$ \\
\hline & Approximate \% of men working in your business in relation to total & $\%$ \\
\hline \multirow{5}{*}{ 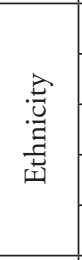 } & Approximate $\%$ of black employees & $\%$ \\
\hline & Approximate \% of Caucasian employees (Europeans or European origin) & $\%$ \\
\hline & Approximate $\%$ of Native American employees & $\%$ \\
\hline & Approximate \% of employees of North African, Persian or Arabic origin & $\%$ \\
\hline & Approximate \% of workers of other races (Roma, Asian) & $\%$ \\
\hline \multirow{2}{*}{ 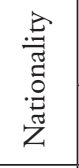 } & Approximate \% of foreign employees & $\%$ \\
\hline & Approximate percentage of national employees & $\%$ \\
\hline \multirow{4}{*}{ 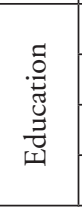 } & Estimated \% of workers with no education or primary school & $\%$ \\
\hline & Approximate \% of employees with compulsory schooling (ESO/Graduate School) & $\%$ \\
\hline & Approximate $\%$ of employees with post-compulsory non-university (Bachelor/FP) education & $\%$ \\
\hline & Approximate \% of workers with university degrees & $\%$ \\
\hline \multirow{4}{*}{ 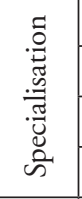 } & Approximate \% of employees engaged in production-operations activities & $\%$ \\
\hline & Approximate $\%$ of employees involved in administration and finance activities & $\%$ \\
\hline & Approximate \% of employees involved in sales and marketing activities & $\%$ \\
\hline & Approximate \% of employees involved in legal activities and human resources & $\%$ \\
\hline 4. & The approximate $\%$ of employees with temporary contracts & $\%$ \\
\hline 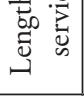 & The approximate $\%$ of employees without temporary contracts & $\%$ \\
\hline$\ddot{\Xi}$ & The approximate $\%$ of employees with less than three years tenure in present job & $\%$ \\
\hline$\stackrel{\Xi}{\oplus}$ & The approximate $\%$ of employees with more than three years tenure in present job & $\%$ \\
\hline
\end{tabular}

\section{If you need more information about the study please contact}

Prof. Dr. Rafael Triguero: email: rtriguero@us.es

Thank you so much for you time. 


\section{Note}

$1 \quad$ Article derived from the doctoral thesis: "La gestión de la diversidad en las organizaciones a través de las prácticas de los recursos humanos" presented by Rafael Triguero in 2010, Universidad de Sevilla, Seville, Spain. Available from Dialnet.

\section{Acknowledgements}

The authors acknowledge the editorial work of Joao Mauricio (editor) and Beatriz Toriello (editorial secretary) and the two anonymous referees who made helpful and valuable comments on earlier versions of this paper. All errors and omissions remain our responsibility.

\section{About the Authors:}

1. Rafael Triguero-Sánchez, PhD. in Business Administration, University of Seville, Seville, Spain. E-mail: rtriguero@us.es ORCID

iD 0000-0003-3730-3972

2. Jesus Peña-Vinces, PhD in Economics and Business, University of Seville, Seville, Spain. E-mail: jesuspvinces@us.es ORCID

\section{iD 0000-0001-8962-7608}

3.Jorge Guillén, PhD in Economics, West Virginia University, USA, ESAN Graduate School of Business, Lima, Peru. E-mail: jguillen@esan.edu.pe

\section{ORCID}

\section{iD 0000-0002-4511-2108}

\section{Contribution of each author:}

\begin{tabular}{|c|c|c|c|}
\hline Contribution & Rafael Triguero-Sánchez & Jesus Peńa-Vinces & Jorge Guillén \\
\hline 1. Definition of research problem & $\sqrt{ }$ & & \\
\hline $\begin{array}{l}\text { 2. Development of hypotheses or research questions (empirical } \\
\text { studies) }\end{array}$ & $\sqrt{ }$ & $\sqrt{ }$ & \\
\hline 3. Development of theoretical propositions (theoretical work) & $\sqrt{ }$ & $\sqrt{ }$ & \\
\hline 4. Theoretical foundation/Literature review & $\sqrt{ }$ & $\sqrt{ }$ & \\
\hline 5. Definition of methodological procedures & & & $\sqrt{ }$ \\
\hline 6. Data collection & $\sqrt{ }$ & & \\
\hline 7. Statistical analysis & & $\sqrt{ }$ & $\sqrt{ }$ \\
\hline 8. Analysis and interpretation of data & & $\sqrt{ }$ & $\sqrt{ }$ \\
\hline 9. Critical revision of the manuscript & & $\sqrt{ }$ & $\sqrt{ }$ \\
\hline 10. Manuscript writing & $\sqrt{ }$ & $\sqrt{ }$ & $\sqrt{ }$ \\
\hline
\end{tabular}

